\title{
Optimal Coverage Area with Lower Number of Access Point
}

\author{
Riam M .Zaal ${ }^{1}$, Mahmood F. Mosleh², Eyad I. Abbas ${ }^{3}$, Maan M. Abdulwahid ${ }^{4}$ \\ \{reammaged4@gmail.com¹, drmahmoodfarhan@gmail.com² ${ }^{2}$,30013@uotechnology.edu.iq ${ }^{3}$, \\ engmaan.m@gmail.com $\left.{ }^{4}\right\}$ \\ University of Technology ${ }^{13}$, Middle Techincal University ${ }^{24}$, Baghdad, Iraq ${ }^{1234}$
}

\begin{abstract}
With the rapid development in the field of communication networks, an indoor positioning system (IPs) has become extremely popular in recent years. In this paper, we compute the access points (AP's) localization to get the best coverage of the building that takes as a case study and administration of the network. The most interesting researcher topics were computing the Received Signal Strength (RSS) measurement and path loss of the signal. RSS and path loss measurement obtained from different received points distributed in different places of the building. The objective of this technique provides an overview of the available outputs of a standard Wi-Fi signal, which is the RSS from each Access Point. So, it is possible to get a list of the received power coming from all the APs covering the area where the received points are distributed in different locations. The results to determine the best direction at each received point was achieved using Wireless Insite. The methodology is applied over two steps, these are data collecting phase, and localization phase. The case study is implemented simulation results using 3D-Ray Tracing approach based wireless InSite software. This software is a suite of ray-tracing models and high-fidelity EM solvers for the analysis of site-specific radio wave propagation and wireless communication system. The aims of this paper finding the best result of the access points that coverage and transmit a signal to most received points to obtain the lowest cost of the localization method for indoor communication application.
\end{abstract}

Keywords: RSS, Wireless InSite, Path Loss, Access Points.

\section{Introduction}

The wireless communication is widely deployed in various indoor areas such as homes, offices, schools, and the most applied technology on internet services [1]. The increasing of low-cost wireless devices with higher data rates services has been providing for many Wireless Local Area Network (WLAN) deployment across many fields [2]. Wireless Fidelity (WiFi) has been known to one of the most important and providing technologies, which has been applied in different types of indoor environments [3]. Hence, the coverage area of AP devices would be obtained based on the length calculation and optimizing the AP deployment. In context, a combination of algorithm and simulated annealing has been presented by researchers in [4] to predict the coverage area of the AP device based on localized position. Wi-Fi works based on the standards of IEEE 802.11, where it has been selected two unlicensed frequency bands of 2.4 $\mathrm{GHz}$ and $5 \mathrm{GHz}$ to be related to any Wi-Fi-based devices [5]. Gaining access to Wi-Fi networks need communication devices such as the communication between the Access Point (AP) and smartphones [1]. Transmitting and receiving data could be useful to measure the values of signal 
strength and analyzed it using the appropriate parameters to obtain the coverage area. The later has been determined based on the number of distributed AP devices in the targeted area [2]. Placing too many AP devices would increase the total cost, interferences, and noises. On the other hand, placing fewer AP's would result in a gap in coverage, insufficient performance, dead zones, and downtime [6].

The establishing of the optimum placement for AP devices was the most significant of the most significant aspects to be handled by many researchers. As a result, several approaches, methods, and algorithms have been presented for this purpose. The first and oldest approach was selecting the AP location manually and based on the guess of the network designer. However, such a method has been reported over long running time with inaccurate results [7]. Other researchers proposed a mathematical model as in [8], where these models require extra computational time and processes. On the other hand, many researchers presented an algorithm for AP deployment. Such as in [9] the researchers used a Multi-Objective Genetic Algorithm (MOGA) as an optimisation method for achieving maximum coverage area of AP deployment. Meanwhile, other researchers in [10] used simulated annealing techniques, where an empirical propagation model has been presented to obtain the length of the wireless signal in an indoor environment. The main drawback of these presented methods that they didn't consider the effects of different building materials, types of walls, and thickness. Researchers in [11] present an optimal access point deployment in an indoor environment using of Wireless InSite software. However, their study was on single floor deployment and didn't consider the multi-floor effects [12].

The researcher in [13] presents for the localization algorithm for the deployment of AP's based on the simulation measurement of RSS. On the other hand, the researcher in [14] presented "Indoor location for safety applications using wireless networks", Indoor location with Wi-Fi allows using the existing infrastructure and devices widely deployed in buildings such as airports, train stations, hotels, etc [15]. In line with this contribution, an investigation for the proper deployment of APs in building are presented. Such investigation has been carried out by using Ray- Tracing approaches based on Wireless InSite software [16]. Results obtained from the implementation of such software was based on the parameter of path loss and received power. The presented deployment method for our targeted area building could achieve full coverage areas with fewer AP devices in order to reduce the total implementation costs.

\section{Indoor Wave Propagation Characteristics}

In order to measure the performance and characteristics of wireless communication networks, there are several key parameters to be considered with the investigation will be discussed in this section. On the other hand, the different type of building materials has a significant impact on the wave propagation as a function to the frequency [12]. Hence, in this paper frequency dependency of $2.4 \mathrm{GHz}$ on different materials properties were considered.

\subsection{Multipath Phenomena}

Which represents the phenomenon of transferring multiple copies of the original signal between the transmitter and the receiver. Multipath propagation has a significant impact on indoor wireless communication and caused by exposure to barriers, obstacles, objects, and human bodies [17]. The received signal can be represented by 


$$
f(x)=\sum_{n=0}^{N-1} \rho_{n} e^{j^{\phi} n} \delta\left(t-\tau_{n}\right)
$$

\subsection{Path loss}

Path loss (PL) represents the reduction in power level and density for the electromagnetic wave when propagated from the transmitter to the receiver [18]. PL has a major significance to specify the location of the transmitter and determining the amount of received power and sensitivity values of the receivers. In addition, it affected by many parameters of separation distance, multipath propagation, reflection, diffraction, and scattering. Which can be calculated as [18]:

$$
P L(d) d B=\overline{P L}\left(d_{0}\right)+10 \alpha \log \left(\frac{d}{d_{0}}\right)
$$

Where $\overline{P L}\left(d_{0}\right)$ is average path loss at the separation distance $d_{0}, \mathrm{~d}$ is the distance between the transmitter station and each receiving point, and $\alpha$ is the path loss exponent.

\subsection{Received Power}

Another important parameter to be handled with the characteristics of multipath propagation is the received power (PR), which represents the decreasing amount in signal power when transfer between the transmitter and the receiver. PR can be calculated based on [16]:

$$
P_{R}(d B m)=10 \log \left(\frac{P_{t} \lambda^{2} G_{t} G_{r}}{16 \pi^{2} d^{2}}\right)+30(d B)-L_{s}(d B)
$$

Where $L_{s}$ is the additional losses of cables, $\lambda$ is the wavelength, $G_{t}$ and $G_{r}$ are the transmitter and receiver antennas gain respectively. and $P_{t}$ is the transmitter power.

\section{Proposed System}

The electrical department in the university of technology was selected for modelling purposes, where the network and its operational performance then incorporated along the model process. The simulated building is shown in Fig. 1 as a result of the simulation using wireless Insite. The network has been designed by deploying access points and received points in the overall simulated building, where it has been selected a powerful type of AP devices and distributed within each floor. The total number of AP devices on each floor and the received point locations can be seen in Table1. The height of each AP and received points were 2.5 and 1 meter respectively. The distribution location of each AP and received point per each floor can be seen in Fig. 2. In addition, the properties of these devices were listed in Table 2. It is worth to mention we have tried to consider most of the materials to define the propagation characteristics in terms of Relative Permittivity $(\varepsilon)$ and Conductivity $(\sigma)$ as recommended by International Telecommunication Union (ITU) [19]. The later values have been listed in Table 3. A bandwidth of $20 \mathrm{MHz}$ was considered catered around $2.4 \mathrm{GHz}$ frequency spectrum. 


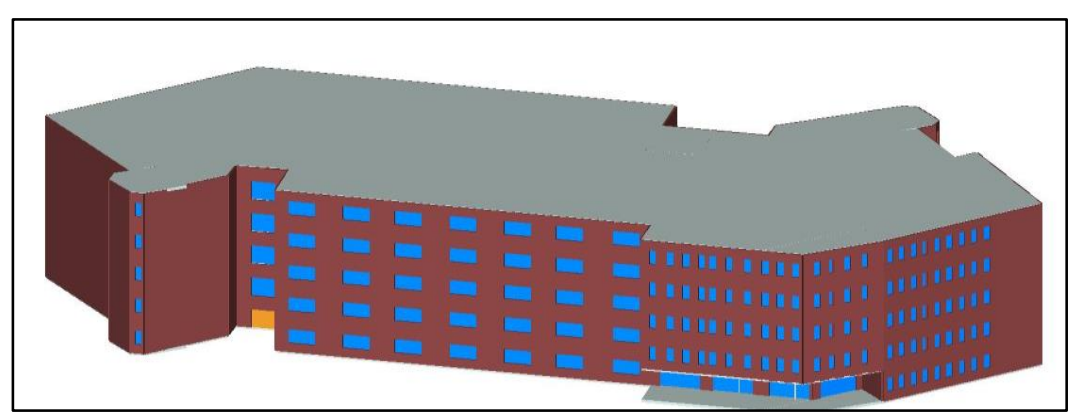

Fig. 1: Wireless Insite geometrical building model

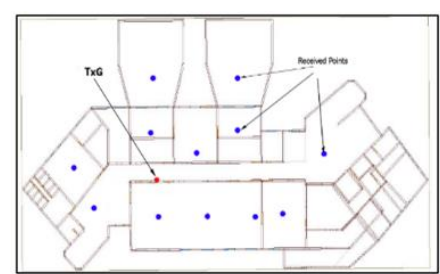

(a)

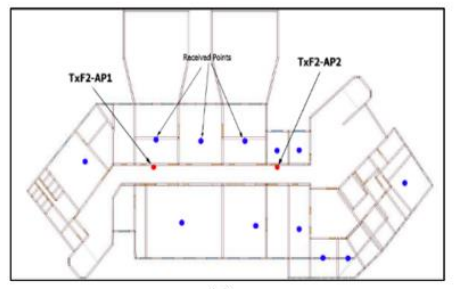

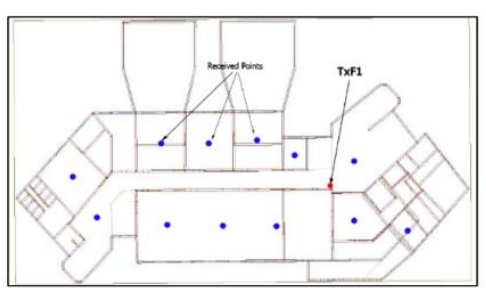

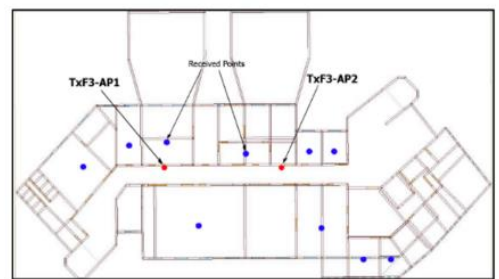

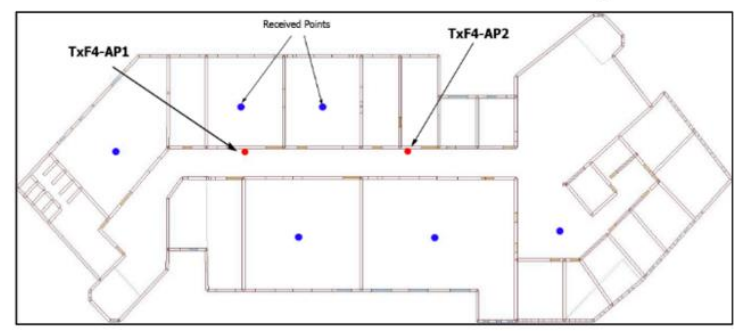

(e)

Fig. 2: The distribution of AP device and received point locations per each floor in the targeted building floors: (a) ground, (b) $1^{\text {st }}$, (c) $2^{\text {nd }}$, (d) $3^{\text {rd }}$ and (e) $4^{\text {th }}$ floor.

Table I. The total number of AP devices and received point locations per each floor.

\begin{tabular}{|c|c|c|}
\hline Floor & No. of AP devices & No. of Received Points \\
\hline G-Floor & 1 & 12 \\
\hline F1 & 1 & 12 \\
\hline F2 & 2 & 12 \\
\hline F3 & 2 & 10 \\
\hline F4 & 2 & 6 \\
\hline
\end{tabular}




\begin{tabular}{|l|l|l|}
\hline total & 8 & 52 \\
\hline
\end{tabular}

Table II. AP and Receiver Antenna Proprieties.

\begin{tabular}{|l|c|c|}
\hline Antenna properties & Tx Antenna & Rx Antenna \\
\hline Antenna type & Omni-Directional & Omni-Directional \\
\hline Input Power $(\mathrm{dBm})$ & 30 & - \\
\hline Gain $(\mathrm{dBi})$ & 9 & 2 \\
\hline E-Plane HPBW & $90^{\circ}$ & $90^{\circ}$ \\
\hline Waveform & Sinusoid & Sinusoid \\
\hline Temperature $(\mathrm{k})$ & 293 & 293 \\
\hline VSWR & 1 & 1 \\
\hline Polarization & $\mathrm{V}$ & $\mathrm{V}$ \\
\hline
\end{tabular}

Table III. Material thickness, conductivity and permittivity values.

\begin{tabular}{|l|c|c|c|}
\hline Materials & Thickness $(\mathrm{m})$ & $\varepsilon$ & $\sigma$ \\
\hline Concrete & 30 & 5.31 & 0.066 \\
\hline Wood & 4.5 & 1.99 & 0.012 \\
\hline Glass & 0.3 & 6.27 & 0.012 \\
\hline Brick & 28 & 3.75 & 0.038 \\
\hline Ceiling Board & 0.9 & 3.66 & 0.001 \\
\hline Floor Board & 2.2 & 1.5 & 0.014 \\
\hline Drywall & 0.9 & 2.94 & 0.021 \\
\hline
\end{tabular}

\section{Results and Discussion}

Using the wireless Insite model for the case described by section 3. The results concerning 8 AP devices distributed within the targeted building was discussed and then the received points located on each floor were analysed. Furthermore, multi-floor communication scenarios will be involved with such an investigation. As a result, it has been evaluating the performance of each AP device in order to cover the entire building based on received power. Figure 3 shows the distribution of the received power concerning each AP labelled as TxG, TxF1, TxF2 AP1 $\mathrm{AP} 2 \ldots$ etc., It can be seen from the general prospects of this figure that there is a reversal correlation between the received power and the distance. In addition, it can be noticed that the serious effect of the concrete layers separated between the floors of the targeted building. As a result, multi-floor communication could be performed for the case of our targeted building and providing reinforcement and support for network coverage in the entire building. 


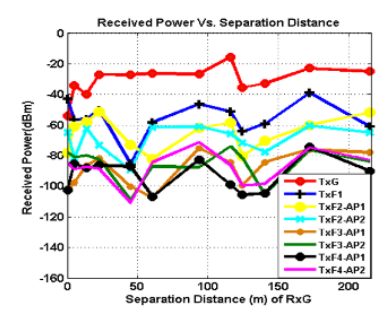

(a)

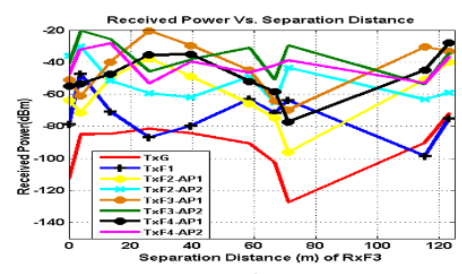

(d)

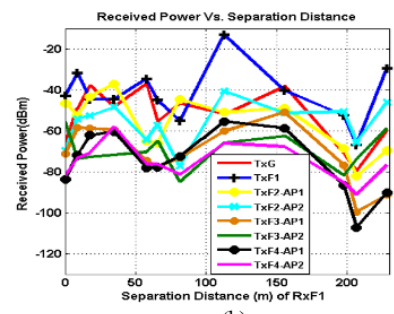

(b)
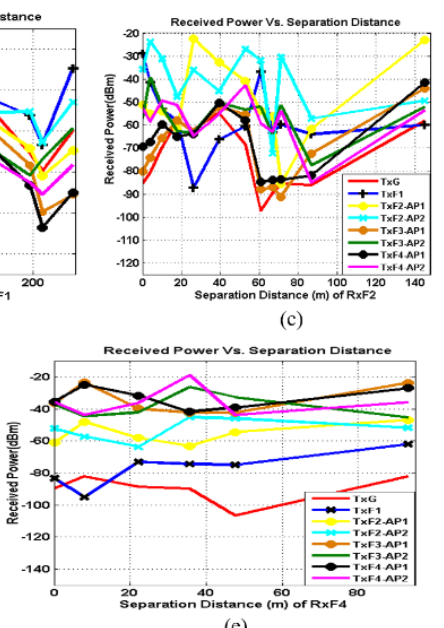

(e)

Fig. 3. The effect of each AP device located in the targeted building on the received points of: (a) ground floor, (b) first floor, (c) second floor, (d) third floor and (e) fourth floor.

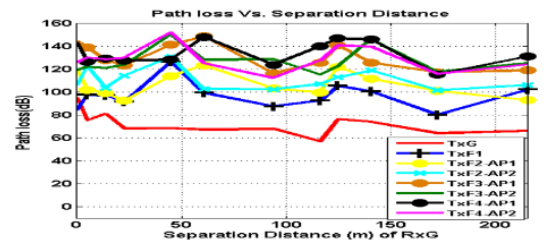

(a)

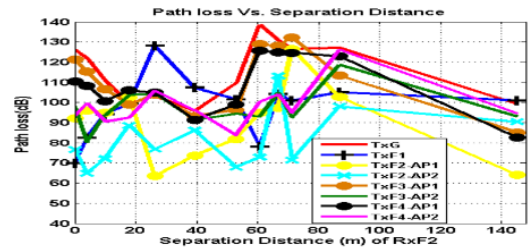

(c)

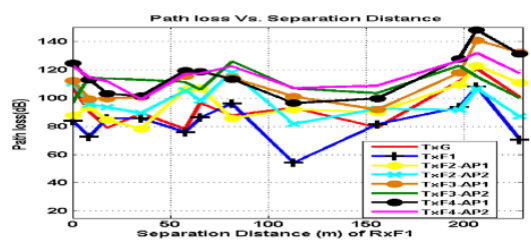

(b)

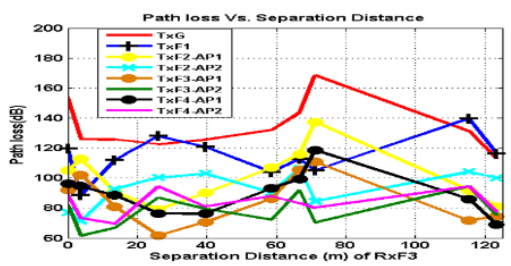

(d)

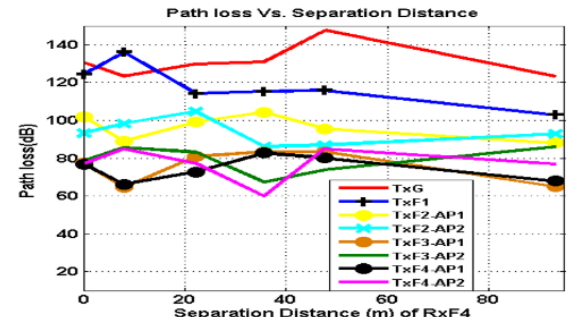

(e)

Fig. 4. The effect of path loss versus separation distance from each AP device to the received points of (a) ground floor (b) first floor (c) second floor (d) third floor (e) fourth floor.

Path loss was another important parameter to be handled with our investigation uisng Wireless InSite software, where it has been clarifying its relation with the separation distance and for both LOS and NLOS scenarios and as seen in Fig. 4. Generally, it is common for longer 
distances high loses. However, such relation can't be seen in a consistent manner due to many reasons related to the allocation of the received points in different rooms within the investigated building, the effect of furniture, obstacles inside the building. For the NLOS scenario represented by the multi-floor communication it can be seen that it suffers from the same previous relation, but with much more losses in power. This is due to various building materials and the separated layers of concrete between the building levels.

In order to get the proper analysis in the manner of network coverage optimization, it has been assumed the minimum legal received power to be $(>=-60 \mathrm{dBm})$ [20] for the entire values of received points obtained from each AP device. Such selection has been recommended and reported to achieve the highest throughput based on VoIP (Voice over IP) application; thus using equ.4, the coverage area for each AP device can be calculated per each floor. The results are listed in Table (IV).

$$
C P=\frac{P_{R} \text { sected }}{P_{R} \text { Total }} \times 100
$$

Where $P_{R}$ represent the number of received point that have a value of power $(>=-60 \mathrm{dbm})$ and $P_{R}$ Total is the total number of received points on each floor in Table I.

Table IV. The coverage percentage (\%) of each AP device and per each floor.

\begin{tabular}{|l|c|c|c|c|c|c|c|c|}
\hline \multirow{2}{*}{$\begin{array}{l}\text { Receive } \\
\text { d point }\end{array}$} & \multicolumn{7}{|c|}{ The coverage percentage of each AP device in each floor } \\
\cline { 2 - 9 } & TxG & TxF1 & $\begin{array}{c}\text { TxF2- } \\
\text { AP1 }\end{array}$ & $\begin{array}{c}\text { TxF2- } \\
\text { AP2 }\end{array}$ & $\begin{array}{c}\text { TxF3- } \\
\text { AP1 }\end{array}$ & $\begin{array}{c}\text { TxF3- } \\
\text { AP2 }\end{array}$ & $\begin{array}{c}\text { TxF4- } \\
\text { AP1 }\end{array}$ & $\begin{array}{c}\text { TxF4- } \\
\text { AP2 }\end{array}$ \\
\hline RxG & $100 \%$ & $75 \%$ & $41.6 \%$ & 0 & 0 & 0 & 0 & 0 \\
\hline RxF1 & $75 \%$ & $91.6 \%$ & $58.3 \%$ & $66.6 \%$ & $41.6 \%$ & $16.6 \%$ & $25 \%$ & $8.3 \%$ \\
\hline RxF2 & $25 \%$ & $58.3 \%$ & $75 \%$ & $91.6 \%$ & $33.3 \%$ & $66.6 \%$ & $33 \%$ & $75 \%$ \\
\hline RxF3 & 0 & $10 \%$ & $50 \%$ & $70 \%$ & $70 \%$ & $100 \%$ & $90 \%$ & $100 \%$ \\
\hline RxF4 & 0 & 0 & $66.6 \%$ & $83.3 \%$ & $100 \%$ & $100 \%$ & $100 \%$ & $100 \%$ \\
\hline
\end{tabular}

Next, the percentage of coverage area related to the total received points of such building for each access point can be calculated based on the result in table IV. The results are listed in Table V which illustrated the percentage of the total coverage area for each AP. It can be seen that almost all AP devices could achieve coverage reaches half the targeted building. For more optimization manner, it can be used fewer AP devices based on the coverage percentage obtained in this table. Better coverage is obtaining by TxF2 AP1nad TxF2 AP2. The reason is the location of such Aps is in the middle area of the target building.

Table V. The percentage of the total coverage area for each AP device within the targeted building

$$
\begin{array}{|l|c|}
\text { Transmitter (AP) location } & \begin{array}{c}
\text { Total coverage area percentage for targeted } \\
\text { building }
\end{array} \\
\hline
\end{array}
$$




\begin{tabular}{|c|c|}
\hline TxG & $46.1 \%$ \\
\hline TxF1 & $53.8 \%$ \\
\hline TxF2-AP1 & $57.6 \%$ \\
\hline TxF2-AP2 & $59.6 \%$ \\
\hline TxF3-AP1 & $42.3 \%$ \\
\hline TxF3-AP2 & $50 \%$ \\
\hline TxF4-AP1 & $42.35 \%$ \\
\hline TxF4-AP2 & $50 \%$ \\
\hline
\end{tabular}

The overall received power for each received points from the corresponding access points are listed in table of appendix A.

Appendix A. The Overall Value of Received power about All building

\begin{tabular}{|c|c|c|c|c|c|c|c|c|c|}
\hline \multicolumn{2}{|c|}{ Received Points } & $T \times G$ & TXF1 & TXF2-AP1 & TXF2-AP2 & TXF3-AP1 & TXF3-AP2 & TXF4-AP1 & TXF 4-AP2 \\
\hline & $R \times 1$ & -54.08 & -43.13 & -78.06 & -64.85 & -103.16 & -77.53 & -102.47 & -85.07 \\
\hline & $R \times 2$ & -34.23 & -56.44 & -60.86 & -81.55 & -97.73 & -80.9 & -85.24 & -88.96 \\
\hline & $R \times 3$ & -39.91 & -56.05 & -58.11 & -62.47 & -85.64 & -79.87 & -88.13 & -87.31 \\
\hline & $R \times A$ & -27.08 & -50.33 & -51.24 & -73.15 & -81.53 & -82.45 & -86.21 & -88.81 \\
\hline & $R \times 5$ & -27.31 & -85.39 & -72.85 & -85.43 & -100.07 & -108.97 & -87.07 & -110.94 \\
\hline Ground & $R \times 6$ & -26.26 & -58.25 & -82.17 & -61.48 & -107.45 & -87.07 & -106.89 & -84.23 \\
\hline Floor & $R \times 7$ & -26.75 & -46.42 & -61.95 & -61.19 & -75.17 & -87.56 & -82.56 & -71.26 \\
\hline & $R \times 8$ & -15.7 & -51.37 & -58.45 & -65.83 & -84.57 & -73.55 & -58.97 & -86.59 \\
\hline & $R \times 9$ & -35.54 & -64.32 & -80.53 & -71.66 & -59.61 & -81.69 & -105.59 & -95.71 \\
\hline & $R \times 10$ & -32.98 & -59.33 & -70.46 & -77.67 & -84.58 & -105.05 & -104.61 & -98.45 \\
\hline & RX11 & -22.92 & -39.07 & -60 & -60.47 & -76.2 & -76.68 & -74.26 & -74.72 \\
\hline & $R \times 12$ & -25.04 & -60.58 & -51.84 & -64.85 & -77.84 & -83.58 & -89.95 & -82.82 \\
\hline & $F \times 13$ & -66.57 & -42.83 & -46.43 & $-69,55$ & -71.18 & -55.57 & -83.66 & -81.81 \\
\hline & FX14 & -49.18 & -31.64 & -52.36 & -54.19 & -58.37 & -73.51 & -71.8 & -73.34 \\
\hline & RX15 & -37.64 & $-44,49$ & -43.29 & -52.48 & -58.63 & -72.72 & -62.1 & -70.68 \\
\hline & RX16 & -48.17 & -44.58 & -37.05 & -48.27 & -59.49 & -71.78 & -60.3 & -57.91 \\
\hline & RX17 & -36.88 & -34.71 & -65.04 & $-64,19$ & -74.43 & -70.32 & -78.07 & -76.08 \\
\hline Firat & RX18 & $-55,34$ & $-45,07$ & -65.99 & -57.12 & -77.46 & -64.9 & -77.59 & $-76,18$ \\
\hline Floor & RX19 & -46.58 & -55.15 & -44.47 & -77.19 & -73.17 & -84.77 & -72.35 & -81.36 \\
\hline & $R \times 20$ & -51.89 & -13.11 & -50.98 & -40.57 & -60.1 & -65.72 & -55.27 & -65.04 \\
\hline & RX21 & -38.15 & -40.29 & -48.76 & -51.22 & -50.75 & -62.32 & -58.67 & -67.67 \\
\hline & $R \times 22$ & -71 & -525 & $-68,41$ & -50.6 & -76.77 & -81.78 & -86.7 & $-85,4$ \\
\hline & $R \times 23$ & -79.72 & -66.91 & -81.87 & $-65,41$ & -99.64 & -73.87 & -107.12 & -91.02 \\
\hline & $R \times 24$ & -59.82 & -29.42 & -69.63 & -45.93 & -91.31 & -58.76 & -90.04 & $-76,63$ \\
\hline & RX25 & $-85,31$ & -28.85 & -51.27 & $-35,66$ & -80.26 & -57.16 & -69.38 & -52.42 \\
\hline & $R \times 26$ & -80.91 & -41.39 & -55.13 & -23.83 & -74.27 & -39.23 & -67.34 & -58.7 \\
\hline & RX27 & -69.89 & -53.08 & -53.96 & -31.13 & -65.6 & -52.71 & -59.72 & -49.45 \\
\hline & RX28 & -58.22 & -58.45 & $-61,41$ & -47.59 & -57.92 & -62.69 & -65.03 & -51.51 \\
\hline & RX29 & -62.08 & -87.2 & -22.56 & -35.94 & -62.99 & -63.28 & -63.96 & -64.82 \\
\hline Second & RX30 & -54.77 & -66.37 & -32.66 & -45.27 & -52.31 & -50.23 & -50.42 & -55.13 \\
\hline Floor & RX31 & $-68,63$ & -60.58 & -40.89 & -26.95 & -55.38 & -53.36 & -57.86 & -42.67 \\
\hline & RX32 & -97.45 & -37.05 & -53.86 & -31.9 & -87.96 & -51.99 & -84.62 & -59.29 \\
\hline & RX33 & -89.75 & -63.29 & -56.24 & -72.27 & -87.09 & -63.73 & -83.93 & -63.01 \\
\hline & RX34 & -85.53 & -59.82 & -85.5 & -30.44 & -91.28 & -51.42 & -83.64 & -53.79 \\
\hline & RX35 & -86.06 & -64.05 & -61.78 & -57.14 & -72.37 & -77.56 & -81.9 & -85.15 \\
\hline & RX36 & 58.17 & -59.9 & -23.1 & -49.43 & -44.14 & -52.12 & -41.56 & -53.62 \\
\hline & RX37 & -112.86 & -78.67 & -64.01 & -35.99 & -51.2 & -41.14 & -55.15 & -47.83 \\
\hline & RX38 & -84.97 & 47.61 & -71.61 & -30.39 & -61.18 & -20.45 & -53.56 & -32.18 \\
\hline & RX39 & -84.74 & -70.84 & -49.74 & 51.64 & -39.92 & -25.73 & -47.39 & -28.33 \\
\hline & $R \times 40$ & -81.62 & -66.92 & -38.1 & 59.41 & -20.68 & -45.85 & -35.48 & -53.41 \\
\hline Third & RXA1 & -84.44 & -79.77 & -49.02 & -62.00 & -29.66 & -38.39 & -35.16 & -39.78 \\
\hline Floor & $R X 42$ & -90.76 & -63.05 & -65.97 & -49.17 & -45.19 & -31.11 & -5212 & -46.78 \\
\hline & RX43 & -102.52 & -71.71 & -74.98 & -65.26 & -64.32 & -50.95 & -58.46 & -42.18 \\
\hline & RXA4 & -127.49 & -63.9 & -96.33 & -43.46 & -69.76 & .29 .49 & -77.42 & -39.04 \\
\hline & RXAS & -90.25 & -98.52 & -50.83 & -63.2 & -30.64 & .533 .66 & -44.9 & -53.26 \\
\hline & RXX46 & -71.79 & $-76,2$ & -40.09 & -59.05 & -33.43 & -34.22 & -27.9 & -36.58 \\
\hline & RX47 & 89.57 & -53.27 & -60.98 & -52.24 & -36.35 & -37.3 & -35.79 & -35.78 \\
\hline & $R \times 48$ & 82.34 & -95.04 & -48.06 & -57.27 & .23 .44 & -44.64 & -25.07 & -43.9 \\
\hline Fourth & RXA9 & 85.72 & .73 .12 & .58 .08 & .63 .69 & -39.8 & -4216 & -31.63 & -36.24 \\
\hline Floor & RX50 & 89.86 & .74 .35 & .63 .17 & -45.25 & -42.39 & .26 .33 & -41.77 & -19.02 \\
\hline & RX51 & -106.5 & .74 .86 & .54 .58 & -45.87 & -42.4 & -32.75 & -39.12 & 43.93 \\
\hline & RX52 & -82.23 & -61.97 & .46 .99 & 51.84 & .23 .96 & -45.26 & -26.9 & 35.84 \\
\hline
\end{tabular}

Table VI. A best coverage access point that has high received power

\begin{tabular}{|c|c|c|c|c|}
\hline \multicolumn{2}{|c|}{ Received Points } & TxG & TxF2-AP1 & TxF4-AP2 \\
\hline \multirow{2}{*}{ Ground Floor } & RX1 & -54.08 & -78.06 & -85.07 \\
\cline { 2 - 5 } & RX2 & -34.23 & -60.86 & -88.96 \\
\hline
\end{tabular}




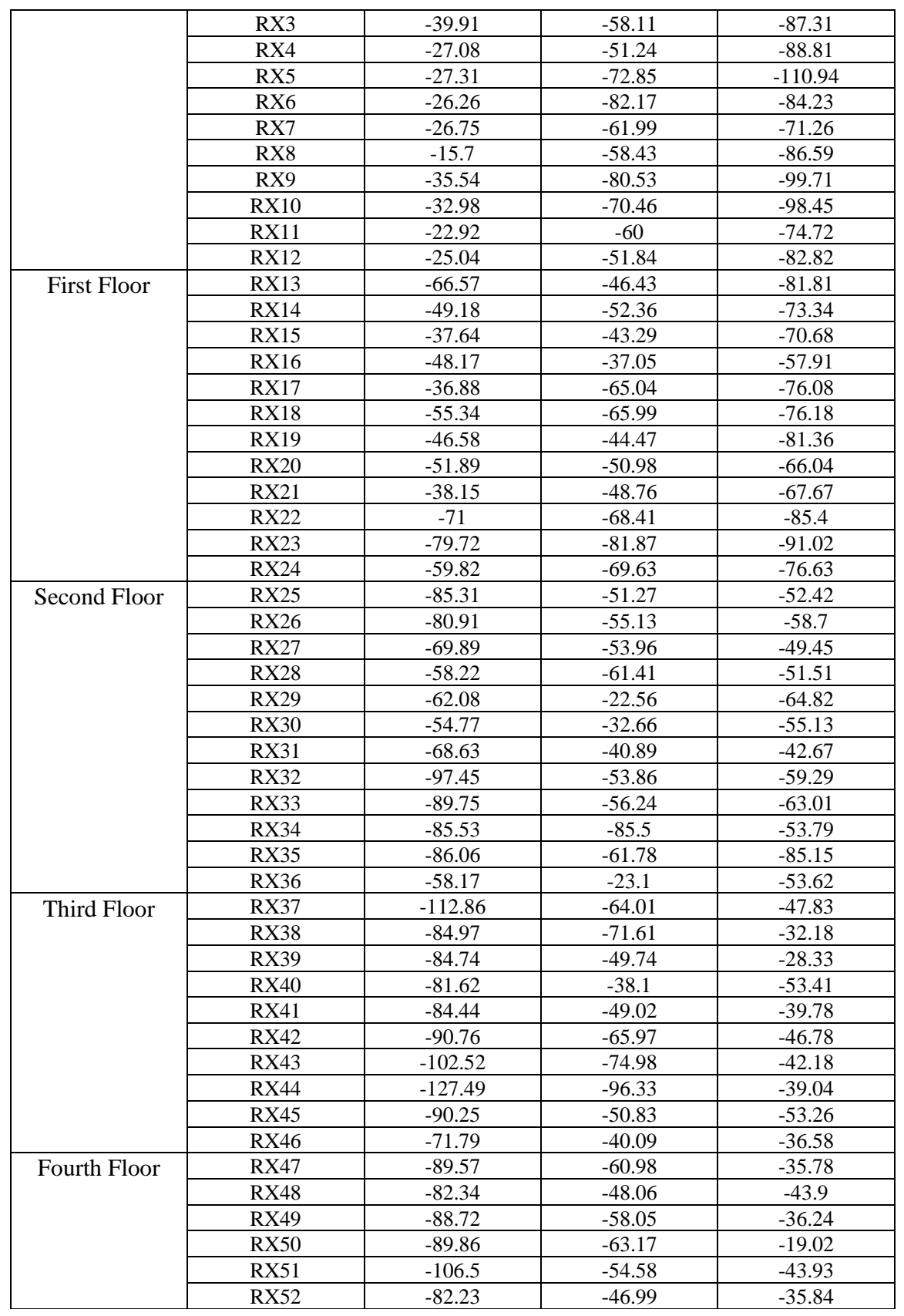

From all results, we can suggest only 3 AP which are (TxG, TxF2, TxF4) to obtain (94.23) \% coverage area instead of 8 which leads to reduce the cost and interface. In table VI, as shown below, we suggested that the best coverage access point that covers all buildings and gets the best value of received power. 


\section{Conclusion}

This paper presents the optimum depoyment of APs for indoor localization method. Two Indoor Wave Propagation Characteristics have been presented in this paper. This includes the received signal strength (RSS) and Path Loss (PL) based on transmitted signals from access points that distributed in the building. The localization algorithm was carried out in two steps, firstly, the modeling case study using a special software application (Wireless InSite package) and then followed by computing (RSS) and (PL) to achieve the best coverage of the building with the smallest number of access points. The computed result indicates three access points achieved good are the optimum selection of AP locations for deployment.

\section{References}

[1] Nugroho, M.A., Wibowo, F.W.: Mapping of Quality of Service Parameter with Monitoring End-toEnd Method of ITU-T Y.1541 Standard in The Hotspot Area. Advanced Science Letters, vol. 20, no. 1, pp. 259-263, (2014)

[2] Mc Gibney, A., Klepal, M., and Pesch, D.: A wireless local area network modeling tool for scalable indoor access point placement optimization. Proceedings of the 2010 Spring Simulation Multiconference. Society for Computer Simulation International (2010)

[3] K'arn' '1k, J., and Streit. J.: Summary of available indoor location techniques IFAC-PapersOnLine, vol 49 pp 311-317, (2016)

[4] Puspitasari, N.F., Al Fatta, H., and Wibowo, F.W.: Implementation of greedy and simulated annealing algorithms for wireless access point placement in 2015 3rd International Conference on Artificial Intelligence Modelling and Simulation (AIMS) pp 165-170, (2015)

[5] Na, C., Chen, J.K., and Rappaport, T.S.: Measured traffic statistics and throughput of IEEE $802.11 \mathrm{~b}$ public WLAN hotspots with three different applications IEEE Transactions on Wireless Communications vol B pp 3296-3305, (2006)

[6] Hussain, T.H., and Salman, A.A.: Indoor access point optimization using differential evolution,” In Proceedings of the Second Kuwait Conference on e-Services and e-Systems. ACM, p. 22, (2011)

[7] Anderson, H.R., and McGeehan, J.P.: Optimizing microcell base station locations using simulated annealing techniques, in: Proceeding of the 44th IEEE Conference on Vehicular Technology, pp. 858-862, (1994).

[8] Lee, Y., Kim, K., and Choi Y.: Optimization of AP placement and channel assignment in wireless LANs in 27th Annual IEEE Conference on Local Computer Networks pp 831-836, (2002)

[9] Maksuriwong, K., Varavithya, V., and Chaiyaratana, N.: Wireless LAN access point placement using a multi-objective genetic algorithm in SMC'03 Conference Proceedings IEEE International Conference on Systems, Man and Cybernetics Conference Theme-System Security and Assurance (Cat. No. 03CH37483) vol. 2, pp 1944-1949, (2003)

[10] Kondee, K., Aomumpai, S. and Prommak C.: A novel technique for reference node placement in wireless indoor positioning systems based on fingerprint technique ECTI Transactions on Computer and Information Technology (ECTI-CIT) vol. 9, pp 131-141, (2015)

[11] Shareef, O.A., Abdulwahid, M.M., Mosleh, M.F., and Abd-Alhameed, R.A.: The optimum location for access point deployment based on RSS for indoor communication International Conference on Modelling and Simulation (UKsim2019) vol 20 pp 2.1(2019).

[12] Alshami, I.H., Ahmad, N.A., Sahibuddin, S., and Firdaus, F.: Adaptive Indoor Positioning Model Based on WLAN-Fingerprinting for Dynamic and Multi-Floor Environments. Department of Computer Science, Islamic University of Gaza, Palestine, (2017)

[13] Abdulwahid, M.M., Al-Ani , O.A.S., Mosleh, M.F., Abd-Alhmeed, R.A.: Optimal Access Point Location Algorithm Based Real Measurement for Indoor Communication. Computer Engineering Techniques, Middle Technique University, Baghdad, Iraq, April 2019.

[14] Barceló-Arroyo, F., Ciurana, M., Watt, I., Evenou, F., De Nardis, L., Tome, P.: Indoor location for safety applications using wireless networks", Universitat Politecnica de Catalunya France Telecom R\&D , University of Rome La Sapienza, Swiss Federal Institute of Technology. 
[15] Hameed, A., Ahmed, H.A.: Survey on indoor positioning applications based on different technologies", Department of Computer Science and Software Engineering Jinnah University for Women Karachi, Pakistan, (2018)

[16] REMCOM Inc., "The Wireless InSite user's manual." version 2.6.3, romcom inc., 315 s. allen st., suite 416 state college, pa16801, November 2012, (2009)

[17] Farahneh, H., Khalifeh, A., and Fernando, X: An outdoor multi path channel model for vehicular visible light communication systems," in 2016 Photonics North (PN). IEEE, pp. 1-1, (2016)

[18] Kim, M.D., Liang, J., Yoon, Y.K., and Kim, J.H.: 28GHz Path Loss Measurements in Urban Environments using Wideband Channel Sounder. in Proceedings of the 2015 IEEE International Symposium on Antennas and Propagation \& USNC/URSI National Radio Science Meeting, IEEE, Vancouver, BC, Canada, (2015)

[19] Effects of building materials and structures on radio wave propagation above about $100 \mathrm{MHz}$. Recommendation ITU-R P.2040-1, pp. 22-23, (2015)

[20] Microwave Journal, Prt-5G: Will The mmWave Link Work?, Andreas Roessler, (2017) 